\title{
La Odisea de Chocano
}

\author{
(Cuba y Sto. Domingo: 1908)
}

\author{
por Luis Álberto SÁnChez
}

Aunquie, al partir de España, por Bilbao, Chocano declaró al corresponsal de "El Liberal" de Madrid que se dirigía al Perú, llamado por su gobierno, la verdad es que no pasó de Centroamérica, donde asentó sus reales por más de doce años.

Las desazones de los últimos tiempos le habían turbado, sin amedrentarle. Se hallaba en la plenitud de su energía tanto biológica como literaria. Aquel año de 1908, además de "Fiat Lux", libro antológico por excelencia, había escrito numerosos poemas, encendidos de la pasion reivindicatoriá que le arrebataba, tanto en su protestāocontraucientoslipersonajesoy métodos de la España de entonces, cuanto en la reafirmación hiperestésica de su incoercible ego. Es probable que, en adelante, no produjera con tan prolijo esmero, y que su obra fuese un boceto o esquema de algo que no alcanzó a coronar ya. Por lo mismo, sus dichos, escritos y actos de ese tiempo deben ser ponderados cuidadosamente.

En Marzo de 1908, poco antes de abandonar la Península y de que el Banco de España resolviera adoptar contra él una actitud sañuda, apelando contra el decreto del juez que había exonerado al poeta de presentarse ante la Justicia en el "affaire" de aquellos tres malandrines, ex-empleados del propio Banco dos de ellos, Chocano había escrito una hasta ahora olvidada composición, titulada "Self Help", que, aparecida en un periódico de Guatemala, constituye una como respuesta polémica al canto "A Roosevelt" de su amigo, prologuista y corresponsal Rubén Darío. (1)

(1) "La República", Guatemala, 14 de Marzo de 1908. 
Es probable que de esa misma época date la por muchos años discutida y fustigada composición "Fin de raza", que empieza: "Raza de leyenda, país de Museo, / España es como una macabra visión". Pues, a poco de incorporarse a la vida literaria de las Antillas, manifestó el poeta un renacido o recalentado amor a España, según iremos viendo, y, algo más tarde, escribiría una respuesta a sí mismo, bajo el título de "Fe de raza", cuyo primeros versos dicen: "Raza de Alegria, pais de sol y oro / España es como una radiante visión". (2) Las cartas a Rubén en aquel período y hasta 1912, revelan el comején de regresar a Madrid, como un triunfador, en el arte y el dinero, que mordía la insaciable soberbia del poeta. (3) El hecho es que el 19 de Junio de 1908 tenemos la primera noticia exacta del arribo de Chocano a La Habana, a través de un suelto de "El Diario de la Marina";

"Anoche recibimos la visita del esclarecido poeta hispanoamericano, que se ha hecho ilustre y popular en España" (4)

"La Discusión" del día siguiente es un poco más explícita, pues nos revela una empresa casi totalmente ignorada que Chocano había puesto en marcha en Madrid:

"Procedente de Madrid, donde dirige la importante publicación 'América española', ha llegado a ésta, de paso para Guatemala. el ilustre poetả peruano. La popularidad y el prestigio de Santos, Chocano eluden toda presentación" (5).

"Figaro", donde tendrá la más amplia acogida el poeta, se refiere a la mencionada revista como uno de los más fructíferos

(2) Bajo el rubro de "Las dos Españas", Chocano recogió ambas composiciones que datan de fechas diferentes: la primera apareció sin forma en "La República" de Guatemala, de 1908, la otra acaso de fines del mismo año o comienzos del siguiente. Ver "Obras completas", México, Aguilar, 1955, p. 839.

(3) Ghiraldo, "El Archivo de Rubén Darío", Buenos Aires, Losada, 1941.

(4) "El Diario de la Marina", La Habana, 19 de Junio de 1908.

(5) "La discusión", La Habana, 20 de Junio de 1908. Deseo dar las gracias públicamente a mi ocasional, pero eficientísimo y diligente colaborador en lo tocante a la permanenca de Chocano en Cuba, el señor, Luis E. Vera, entonces (1951) desterrado venezolano refugiado en La Habana. Gracias a él pude recoger numerosas composiciones poéticas y prosas que publiqué en la arriba mencionada colección de "Obras completas"... ahora por completar. 
proyectos de Chocano. El número programa de "La América Española", parece haber sido el único que salió a luz y alcanzó a circular, al menos en Cuba.

Max Henriquez Ureña, que se hallaba entonces en La Habana, me ha referido dos o tres anécdotas, cuya primicia quisiera desvelar ahora, pero cuya confirmación espero antes. Una de ellas presenta al poeta en situación económica angustiosa, pero lleno de orgullo, tratando de salir de sus aprietos con arrogancia, sin mengua alguna de su prestigio ni de su amor propio. El administrador de "El Figaro," Catalá, en el que ejercía funciones de piloto el poeta Manuel S. Pichardo, comprendió que, bajo la apariencia de una transacción cambiaria, se ocultaba la falencia del recién llegado, que hurgaba magín y caletre para urdir nuevos modos de agenciarse la vida, sin detrimento de su congénita soberbia.

La silueta que nos ofrece un cronista de "El Diario de la Marina" es muy significativa:

"Mientras uno leia 'La Lucha', miré por encima de su hombro y vi una caricatura y un retrato. Del retrato no me quedó nada impreso. De la caricatura, sí. Vi un bigote de borgoñón, negro, felpudo, atenazado, guías arriba en ondulaciones desdeñosas. Una nariz de suaves lomos, amplios ventanales y movible perendengue, el pelo en avant hacia el cogote. $\mathrm{Y}$ todo ello altivo, movible, interrogador, serio... Pertenecen estos rasgos a un absentista catalán o] a ưn prestidigitador portugués, afirmé yo con aplomo. Y el otro me dijo. "Tiene usted una vista padre: es cefectivamente Chocano, poeta natural del Perú, vecino de todas partes" ...Es Chocano, uno de los vates del Pacífico, que son dos: Chocano y Rubén. Viene de España cargado de aplausos, abrumado de loas, abatido de consideraciones sociales, de elogios literarios. Lo primero que hizo Chocano al llegar a La Habana fue visitar al señor Conde Kostea (6), y así se puede decir que vino 'a por atún y a ver al Duque'. Y, después de ver al Duque, habló mal de la Academia española. Chocano es nuestro huesped y huesped tan ilustre como el más emblasonado castellano soñaría para admirador de la Duquesa y honra de sus yantares. Tengo a Chocano por el más poeta de América" (7).

La situación financiera del poeta era, sin duda, precaria, y eso le impulsó a acelerar su primera presentación pública en Cudivia.

(6) El Conde Kostia era el seudónimo del escritor Aniceto Val-

(7) “El Diario de la Marina" La Habana. 25 de Junio de 1908. 
ba, que se realizó el 23 de Junio de 1908, ante un pequeño grupo de escritores y periodistas reunidos en el Ateneo. Elías Entralgo, se refiere al suceso del siguiente modo:

"En el verano de 1908, encontrábase en nuestra capital José Santos Chocano. El 23 de Junio de ese año, en la tardecica, brindó la lectura de algunos de sus poemas a una treintena de literatos y periodistas. La recitación ante concurrencia numerosa la daría en medio de un concierto musical, el domingo 6 de Setiembre, y, después, ante público más abundante ofrecería otra en una velada literario-musical, que se celebró en el Instituto Musical de La Habana, el 20 de Setiembre, poco antes de su última (sic) partida de Cuba, y en la que, por cierto, el único número que se suprimió del programa anunciado fue el discurso de Rafael Fernández de Castro. Pasaba el aedo peruano por un momento muy vivaz de su producción lírica y estaba todavía en uno respetable de su vida pública, después de tan contrastadas peripecias, algunas muy feas y múy distantes del rebelde fulminador de "Iras Santas' y del antiguo prologado de Manuel González-Prada. No hay que decir nada más del segundo, y, si, algo del primero. Ya su inspiración vigorosa, preferentemente enardecida por los temas de la naturaleza, la cultura y la historia de nuestra América, había cultivado el clasicismo, el romanticismo y el modernismo, $y$, al visitarnos, frisando en los treinta y tres años, se acababa de permitir, en el libro "Fiat Lux", la afirmación de séguridad crítica de unanautoantología. Se le ha reparado a su personalidad literaria la imaginacinó atropellada y barroca. Entre nosotros dejó recuerdo de ella en prosa, si bien en una 'crónica lírica' que, con el título de "Entre dos Islas' (Cuba y Santo Domingo) publicó en 'El Fígaro' del 23 de agosto de 1908, tuvo la peregrinidad de escoger como símbolo de La Habana antigua, a la calle de Obispo, sin que ninguna cosa le dijeran al respecto ni la Alameda de Paula, ni la Plaza de Armas, ni la de la Catedral, quien sabe si llevado por su fantasía erótica para ver que 'los almacenes no hacen más que improvisar en los cristales de sus escaparates, espejos en que se reflejan, asi, al paso, las mujeres ceñidas entre las ballenas de sus corsts voluptuosos y ornamentadas con la pompa de sus sombreros alucinantes' ...Traigámoslo a La Habana nuevamente para despedirlo - por esta disertación- diciendo que los oyentes de aquel atardecer suyo en el Ateneo, muchos de los cuales ya conocían y admiraban al poeta, se encantaron con el declamador, lo mismo cuando les arrojó el torrente de catorces imágenes -algunas disparatadas y algunas repetidas- en los catorce 
versos del soneto 'La magnolia', que cuando les leyó este más sobrio 'Mensaje' que acababa de componer en La Habana..." (8)

Entre la "Treintena" de asistentes a esa recitación preliminar estaban Lola Tió, Amalia Castillo de González, Patria Tió de Sánchez Fuentes, Dulce María Borrero de Luján, Santos Fernández Valdivia, Manuel S. Pichardo, Jesús Castellanos, José Manuel Carbonell, Alfonso Hernández Catá (en sus 23 años), J. Hernández Mijares, José María Cartina, Próspero Pichardo, Carlos Manzanares, Collejas, Catalá, Carrera, Horta, Mendoza, Lorenzo Angulo, los hermanos Robreño, etc. "El Figaro" resume la impresión de los asistentes diciendo:

"Que estábamos en presencia de un poeta de primer orden, lo sabiamos antes de empezar la lectura; de que oiamos a un recitador y lector maravilloso, puciimos convencernos apenas terminó de encantarnos $y$ asombrarnos al terminar la primera poesia".

A partir del 23 de junio, consecuencias auspiciosas del buen éxito recitativo, Chocano inicia sus colaboraciones en "Figaro" y una columna diaria en "El Diario de la Marina". No podría asegurarse que de la mejor calidad literaria: y se explica...

En aquella primera recitación, Chocano leyó, como dice Entralgo, su "Mensaje 'ala Patria". etras

Los antecedentes inmediates AP justificaban el entusiasmo por el Perú ni la melancolía por la ausencia, que Chocano muestra en ese poema. No olvidemos: en 1904, el gobierno de Lima había aceptado su renuncia de la Encargaduría de Negocios en Bogotá, sin ninguna protocolaria expresión de gracias; poco después, había ocurrido una pequeña Vía Crusis en Lima, cuando el poeta pasaba como enviado especial de Nicaragua, y, por último, en 1906, había sufrido una tácita separación del Servicio con un decreto sobre asuntos financieros, redactado en términos desagradables, si no ofensivos. (9)

Empero, el "Mensaje a la Patria", leido en privado el 23 de Junio, y en velada pública el 11 de Julio, no el 6 de setiembre co-

(8) Elías Entralgo, "Un Humoroide en la Presidencia del Ateneo de la Habana." Separata de "Universidad de La Habana", La Habana", La Habana, 1953, p. 31-33.

(9) Véanse capítulos anteriores y pags. cite. de las "Memorias" de Chocano, ed. Nascimento, reproducidas en "Obras completas", cit. p.... 
mo dice Entralgo, quien se refiere a otra presentación se lee con cierto estremecimiento cívico.

¡Oh, Patria! Hasta mi viene tu recuerdo, a manera de un gran viento que hincha las velas de mi nave. Nunca estuvo en mi mástil plegada tu bandera cual si fuese el cansancio con que se posa el ave.

Donde pulsé la lira, supe ganar laureles, supe ganar laureles que deshojé a tus plantas. Tal, si yo pongo el lienzo, tú pones los pinceles; y si yo pongo el mármol, tú pones los cinceles; y si yo pongo el oro, tú pones los troqueles: yo soy el que se inspira, mas tú eres la que cantas...

Tu cantas en mi sangre lo que repite el estro... Acaso tu Amazonas ha sido mi maestro. $Y$ asi es como tus hijos protestarán, acaso, cuando la muerte apague los ecos de mi paso: - Su lira fue de España, pero su canto es nuestro.

Y hoy tu nombre, oh Patria, protege mi camino, me libra del escollo, me impone a la amenaza; yo soy, para tu gloria,poetadperegrinetras que ha recorrido dodos los pueblos de mi raza...

A tí marco hoy mi rumbo: descansaré un instante, $y$, por si acaso es cierto que con amor me esperas, te envío este puñado de versos por delante, como un tropel de blancas palomas mensajeras. (10)

Como siempre, compone un poema auto-biográfico. Se conocen ya todas sus circunstancias. Además, repentista. En ese momento, Chocano produce con facilidad y sin rigor. Las estrofas segunda y tercera, en forma de sextilla y de quintilla con la insólita combinación de terceto monorrimo y de pareados, delata más que habilidad, sometimiento a la rima, sonoridad invencible, y esa flaqueza por las consonantes líquidas tan frecuente en los modernis-

(10) Chocano, "Obras completas", cit. p. 906. 
tas, amén del empleo tan peculiar del alejandrino francés. Por otro lado, el décimo verso ("Su lira fue de España, pero su canto es nuestro") reilera el indo-españolismo pregonado en "Alma América", y hasta parafrasea un verso antiguo: "Ser la mitad de América y la mitad de España".

¿A qué se debe esta porfía? Desde luego a propio designio pero, además, a la evidente decisión de no manifestar ira contra España, pese a los infaustos episodios de su etapa final en ella, y a la presencia de los marinos del "Nautilus" en Cuba, que da pie a Chocano para insistir en su admiración por la antigua Metrópoli de sus evocaciones. Claro está que ambas circunstancias hacen pensar que la composición "Fin de raza" es subsiguiente, y que haberla fijado o fijarla en los comienzos de 1908 podría ser erróneo. No dispongo de elementos bastantes para elucidar en definitiva la cuestión, dado que Chocano tenía por costumbre publicar sus versos varias veces, en distintas revistas y en diversas épocas, y que las revistas lo hacian también por su cuenta, saqueando la producción del poeta más leído y admirado por los hispanoamericanos, indoespañoles 0 hispanoparlantes de entonces.

El "Nautilus" fue un barco español, de guerra: el primero que arribaba a La Habana después de la voladura del "Maine" y del Tratado de Versalles entre Madrid x Washington, que apartó para siempre a Cuba de la tutela política peninsular. Los cubanos, tan vinculados ra lauantigual Melrópoli, "quisieron expresar en esa oportunidad la lealtad de su afecto a España, pese a la Independencia, que fue desde luego también una forma de lealtad, pero a su propia tierra. Chocano aparece como uno de los cronistas más conspicuos de la visita del "Nautilus", a la que dedicó numerosas prosas y versos. Estaba en edad de producir y dejarse escuchar: el silencio era lo que menos le convenía y lo que menos se adaptaba a su carácter.

Las fiestas a los marinos del "Nautilus" fueron abrumadora. No solo los cubanos, sino también, como es natural, los norteamericanos extremaron sus halagos a los nautas peninsulares. Había que suavizar el sacrificio del almirante Cervera y su valerosa escuadra. "Más vale honra sin barcos que barcos sin honra", la heróica frase de Cavite, podía adicionarse ahora: "Más vale honra sin barcos y con dionisiacas reivindicaciones..." Chocano fue, repito, de los más entusiastas. Una de las mejores fiestas la ofre- 
ció el Ministro de Estados Unidos en La Habana. Algo ocurrió la noche anterior, o fue el calor muy grande -era ya pleno verano tropical-. pero el hecho es que Chocano se quedó dormido en el coche que lo conducía. Despertó deslumbrado ante la figura de "la blonda Orosia Figueras", para quien improvisó un galante soneto que termina:

pero, al verte la rubia cabellera, he pensado

que las arpas celestes se han quedado sin cuerdas (11)

Para los marinos escribió algo más consistente: "La nave zarpa", fechada el 8 de Julio de 1908.

Aunque también un impromtu, a que Chocano se dedicó excesivamente durante su etapa habanera, contiene rasgos delatores del original temperamento de su autor. Empieza con el retórico acento de ciertos pasajes de "Alma América":

Es la tarde. Hora triste de largas despedidas.

Abrázanse las almas, sepáranse las vidas.

Un estremecimiento sacude el océano;

y los ojos confunden en el confín lejano,

el revuelo de un ave $y$ el adiós de una mano.

La nave está ÿdilișta parazarpar. El toritos

de un centengr de bocas ise glarganen lo infinito;

y su canto profundo cantan los marineros,

levando el ancla. Oh, canto de sones lastimeros!

Las velas que se tienden hacia la lejanía

han sido orgullo y gloria de nuestra raza un día;

porque ellas se impusieron sobre ignoradas olas,

$y$ se sintieron fuertes y combatieron solas.

El viento que las infla conoce nuestra vieja

y noble historia; acaso por eso es una queja.

Los cuatro últimos versos trascritos pagan demasiado tributo a la rima y a la anécdota. Los cuatro primeros de la segunda estrofa tienen un no se qué de nostalgia que evoca el poema de Mallarmé, "Brisa marina". Coincidencia o reminiscencia, son de

(11) Chocano, "Obras completas", cit. p. 905. . 
neto buen gusto. Termina con una estrofa a la que habría debido amputar el último verso, 0 , si se quiere ser menos exigente, la última parte del último verso, aunque ahi, justamente ahí reside la idea central de la composición. Dice la última estrofa:

\section{- AAdios! ¡Ádios! - El canto marinero se pierde}

Flota la noche negra sobre la anchura verde;

$y, a l$ resonar las lonas entre mares y cielos,

se piensa en el dramático adiós de cien pañuelos.

- AAdios! ¡Ådios! - se borra la playa, solamente

queda una línea. Luego, ya nada... Un sol poniente,

un cielo sugestivo y un mar ilimitado...

Allá en la playa, un hombre que duerme: es el pasado! (12)

¿El poeta habría querido que también "allá en la playa" quedara su pasado de España? Asi me lo parece. Porque es amistosísimo el tono de una crónica suya titulada "Hétema aquí, envidiando". (13) Refiriéndose en ella a la arribada del "INautilus", menciona a "nuestro apreciabilísimo amigo el Excmo. señor Ministro de España, enfundado ceremoniosamente en su fulgurante uniforme".

Era la época de iniciación del cine. Francia había tomado la iniciativa. La nota de Chocano al respecto posee cierto retrospectivo encanto: blioteca de Letras

\section{"Jorge Puccinelli Converso"}

"En casi todos los teatros (de La Habana) siguen escurriéndose las vistas de los cinematógrafos. Pláceme en estas, las recordaciones vivas de los sucesos reales; me abruman en cambio tantas majaderías melodramáticas que inspiraciones paupérrimas echan a vuelo sobre las alas de Lumiére" (14).

De paso, por el poeta sabemos que Julia Fons campeaba en la zarzuela y. Jesus Castellanos en el cuento: Arcades ambo.

Volvamos a los días de la visita del "Nautilus", que interrumpió el primitivo programa de vida y arte de Chocano. Su primer

(12) "El Diario de la Marina", 9 de Julio de 1908. Reproducida en Chocano, Obras compl. p. 905-6.

(13) "El Figaro", La Habana, 30 de agosto de 1908. Obras completas, p. 963.

(14) "El Figaro", misma edición de la nota anterior. 
recital público se realizó en la Sala Espadero del Conservatorio Nacional, que dirigía el señor Hubert de Blanck. Se hallaba en la calle Galiano, número 47. La fecha fijada: 11 de Julio. (15).

El público de entonces tenía pocos entretenimientos, pese a las "flexibilidades" coreográficas de Julita Fons, la lectura de cuentos por sus autores y la aparición del cine. No se entiende de otra manera cómo pudo haber público, en aquella ciudad calurosa, bajo el verano impío, para escuchar no al poeta, sino veinticuatro composiciones, algunas de ellas extensas, un largo poema de presentación y varias partituras musicales. (16) Fue un gran suceso.

"Se encontraba la ideal inspiradora de hermosos versos del bardo festejado, la blonda Orosia Figueras, que brillaba entre el conjunto de bellezas en la Sala Espadero congregado, con todo el encanto indefinible de su belleza evocadora de ensueño".

Así dice, con indudable entusiasmo, aunque dudoso buen gusto, el cronista de "Figaro", con quien el poeta compartiría poco después la tarea de las "Crónicas sociales". Para celebrar el triunfo, se organizó un homenaje en los salones de "El Telégrafo". Pichardo repitió allí parte de su discurso-poema de la velada. Numerosos heptasílabos, no menos de 276 , precedidos y cerrados por un mismo distico alejandrino:

Inca maravilloso, desgranántul collar,verso»

que será el bien más puro que nos venga del mar.

Entre la dilatada versaina, no siempre feliz, hay un fragmen-

(15) "Figaro", 12 de Julio de 1908. Los diarios de La Habana entre el 1 y el 20 de Julio están llenos de notas y alusiones de la presencia del poeía en la Isla. La prensa de provincias, especialmente la de Oriente, se refiere a él en términos encomiásticos muy singularmente entre el 13 y el 26 de Julio. Luego vuelve la actualidad entre el 19 de Agosto y el 30 de Setiembre de 1908.

(16) El programa de la recitación del 11 de Julio, que debo al mencionado señor Luis Eduardo Vera, da una idea de las costumbres literarios de la Cuba de entonces. Helo aquí: Primera parte.- I. Obertura de Mignon (A. Thomas) a dos pianos, ocho menos, arreglo de $M$. Isambert, por las señoritas Ana Puig, Margarita Carrillo, Juanita Ramos, Matilde de Adriansen; II. Cuba a J. Santos Chocano: saludo por M. S. Oichardo; III. La Isla de bronce, poesía por J. S. Chocano; IV. Del libro "Fiat Lux", poesías por J. S. Chocano: Anacronismo, Fuga, 
to de enumeración seudovalorativa de los poetas americanos de la época. Conviene conocerla:

En la corona lírica

de cuádruple florón, que en la frente de América ha colocado Dios, es la Gracia, Darío;

la Bravura, Mirón; la Plástica, Lugones; Tú, la Fuerza, Señor; Señor, te la legaron Pizarro y Cuactemoc. Por el Rey de la Imagen palmas bato y tambor, Aqui, tabaco y caña y a vuelo mis campanas, llaman a procesión. Acuñas tú, monedas con tu busto, Señor, y añades a la lira una octava de sol. Tú, si, que llegar puedes como un Conquistador! Si te has "cansado mücho"z (17) reposo y paz te doy, y mientras te dispongo hamaca y mecedor, las galas te presento que el Hado me otorgó. en oveja al león... Aquí, tabaco y caña mis predilectos son de los riectarios jugos que mi suelo filtró. Ven, gózalos conmigo, al fragrante rumor de ceibas y de palmas y entra en mi corazón: como la hoja, fuerte, cual la miel, dulce soy. Los ojos de mis hijas, milagros que hizo Dios, tornarán un instante en paloma ul condor, al épico en trovero,

El arco de Ulises, El rayo,isol y Cuná, Crisol, La novia abandonada, Intima, Danza griega, Nostalgia. - Segunda parte.- I. Balada, Chopín, por el señor Hubert de Blanck; II. De "Alma América", Poesía por J. S. Chocano: Idilio tropical, En la Armería Real, Pandereta, El añol, La magnolia, Las minas de Potosí, Ll maíz, El ala del ñandú, Ciudad fundada, A una dama de la Corte española, El amor de las selvas, Los caballos de los conquistadores. - Tercera parte.- I. a) Canzone de Solvejg (Grieg), primera audición; b) La ardita (L. Ardit), vals brillante, por la señora Pilar M. de Blanck; II. Del libro inédito 'El Dorado. Epopeya salvaje': Prólogo interior, El sueño heróico, Visión de pesadilla, La danza del viento, El rapto de las amazonas, Noche salvaje, El baño de los caballos, Aquella tarde, Los toros pasan, Dedicatoria el Gran Capitán; III. Mensaje a la Patria, poesía.

(17) Alusión a la composición de Chocano titulada "Nostalgia", inserta en Fiat Lux" Madrid, 1908, que empieza:

Hace ya diez años

que recorro el mundo:

he vivido poco, me he cansado mucho... 
Sigue un largo elogio a las mujeres cubanas. Chocano acató el consejo de Pichardo, $y$, no sólo dejó madrigales en las hojas de album de las hijas de este, sino que inundó los de muchas señoras y señoritas habaneras. En "Obras completas" hemos dado pálida idea de dicha abundancia, patente también en las páginas de "Figaro", "El Diario de la Marina" y "La discusión" de entonces. Botón de ello es el retórico soneto dedicado la señora María Amblar de Pichardo y un leve madrigal que escribió para la niña María Matilde Pichardo:

\section{Madre rubia, hija trigueña \\ ha tenido que nacer, como de la rubia caña sale la trigueña miel}

Los albumes de la señora Tió de Sánchez Fuentes, la señorita Herminia Dolz, y otros ostentan ampulosas y retóricas endechas chocanescas. Cumplíase el vaticinio de Pichardo: se trocaban "el épico, en trovero; en oveja el león".

Inmediatamente después del memorable recital del Conservatorio, Chocano inició una jira poética por las provincias de Matanzas y Las Villas, Pichardo, que era de esta última región, presenta a Chocano en el recital realizado la noche del 16 de Julio, en el teatro "La Caridad", de SantadClara, capital de Las Villas. Fue causi una manifestación política, por su número y fervor. (18). Después de la función, los entusiastas ofrecieron una cena al visitante en el Café Central y, desde ahí dirigieron sendos cablegramas a Rubén Darío y a Nicolás Rivero, en París y Liberty, respectivamente. Ignoramos sí hubo respuesta.

Santiago de Cuba, ciudad tan española, o, mejor, tan criolla, como las de América del Sur, fue escenario de otra apoteosis chocanesca. El clima ardiente, la encantadora posición del valle, rodeado de suaves y verdes colinas, el temperamento de los habitantes, la cercanía de las heróicas leyendas de la reciente guerra por la Independencia, la ubícua presencia de recuerdos y reliquias de Martí y los Maceo, de Estrada Palma y sus heróicos compañeros, daba a aquel lugar un tono especial, apto como pocos para recibir el ardoroso mensaje del poeta de la Naturaleza

(18) "Figaro", La Habana, 19 de Julio de 1908. 
y la Historia americanas. Las crónicus periodísticas asi lo testimonias. Una vez cubierto el programa santiaguero, Chocano se dirigió a la vecina Isla de Santo Domingo. Le acompañaba el joven escritor dominicano Rafael Galván, descendiente del famoso escritor y novelista, padre de "Enrlqutllo", don Manuel Jesús Galvón.

Como aquella visita era sólo un breve paréntesis, Chocano no se despidió esa vez de Cuba, como él acostumbraba hacerlo de todo país que visitaba.

El 24 de Julio de 1908, desembarcaba del vapor "Julia", en ia Ciudad de Santo Domingo, el infatigable y asendereado "poeta de América". He aquí como le saluda el diario principal de la capital quisqueyana:

"Conocedor de toda la América Latina, faltábale conocer Quisqueya, y ha querido hacerle una visita y conocerla no de oídas y por trasmano, sino con la conciencia que entra por los ojos, y se aposenta en el centro, de manera que los dos se orientaron en el conocimiento que desean los informes estúpidos o malévolos que, de tiempo en tiempo, hacen circular los humoristas de pacotilla" (19)

El tono de esta hotaciefteja Cunestado"de espíritu muy característico. La República Dominicana había atravesado por no lejanos períodos de terrible dictadura, como la de "Lilis", que motivara el extrañamiento de don Francisco Henriquez Carvajal, su esposa doña Salomé Ureña, y sus pequeños hijos, los HenriquezUreña. El movimiento modernista había prendido con singular viveza, y tenía por adelantado a Tulio M. Cesiero (1877-1955) quien, ya, desde su primero y juvenil libro, "Notas y escorzos" (1898), había popularizado los nombres de José Enrique Rodó, Vargas Vila, Díaz Rodríquez, Ismael Enrique Arciniegas, Pedro César Dominici y otros. Ese año, Cestero tenía en prensa "Sangre de primavera" que había incluído en "El Jardín de los sueños" (1904). todo ello prosa poemática, como la de "Las Montañas del Oro" 1908.

(19) "E1 Listin Diario", Santo Domingo, Viernes 24 de Julio de 
de Lugones. Junto a Cestero, militaba Rafael Octavio Galván (1877194..), autor de la novela corta "Lidia" (1901); Américo Lugo (1870-1952), famoso ya por la colorida prosa de "Heliotropos" (1904); Pedro Henriquez Ureña (1884-1946) quien ya, desde 1905, había lanzado su primer libro "Ensayos críticos", donde rinde pleitesía a Darío, José Joaquín Pérez (1845-1900), Fabio Fiallo (18661942) y, claro, a D'Annunzio, Wagner y Wilde. Fiallo, dominicano, era considerado como "el poeta del amor". Residía a la sazón en Nueva York, era grande amigo de Darío y cultivaba relaciones epistolares con Chocano. Su libro "Primavera sentimental" (1902) era como un breviario erótico juvenil. Otro grupo de escritores más jóvenes rodeaba a los anteriores, excepto a Henriquez Ureña, que deambulaba por Cuba, Estados Unidos, México, en su terco y fecundo peregrinaje cultural. Entre ellos, Oswaldo Bazil (1884-1946), Altagracia Saviñon (1886-1942), Apolinar Perdomo (1882-1918), Ricardo Pérez Alfonseca (1892-1951), quien intervino en uno de los homenajes a Chocano y, pasado el tiempo, tropezó con la muerte, subitamente/en Lima, poco después de presentar credenciales como embajador en el Perú.

Tuvo nuestro personaje la suerle de contar como padrinos y altos espalderos, a don Federico Henriquez Carvajal, adalid moral del pais, y a Tulio Cestero, su paladín literario. Don Federico, no lo olvidemos, había sido el padrino de José Marti y de Eugenio María de Hostos, en sus arribadas a la República Dominicana: gloriosa coincidehcia:e (20) cinelli Converso"

El primer recital de Chocano en Santo Domingo se realizó el día del Perú, 28 de Julio, en el Casino de la Juventud. El discurso de presentación, antes de la primera parte de recitaciones, corrió a cargo de Henriquez Carvajal; el de introducción a la segunda parte, a cargo de Cestero. Figuraban como organizadores los mejores literatos del país.

Fue otra apoteosis de público y crítica. ¿Podría aquello cicatrizar la abierta herida de España? Parece que, en cierto modo, si. Porque, en medio de los homenajes, Chocano se da tiempo y busca ambiente para escribir nuevos poemas como "Los árboles de América". que un periodista quisqueyano alaba al día siguiente

(20) Cfr. Max Henriquez Ureña, "Breve historia del Modernismo", México, Fondo de Cultura, 1955, Pedro Henríquez Ureña, "La Literatura dominicana", París, Revue Hispanique, 1917. 
del recital (21) y que aparecerá publicado, poco después, en La Habana (22). El poeta se ha prendado del ritmo y rima de su entonces recitadísima composición "Los caballos de los conquistadores", empleando el eneasilabo, ciertos ritornellos poco sono. ros pero expresivos, y multiłud de imágenes no siempre tan sentidas como buscadas. (23)

Empezaba a recuperar su buen humor de antaño, su desplante. Lo revela una interviú de "El Listín Diario" (24)

"El hombre más desgraciado de toda la Isla es en el día José Santos Chocano. Están matándolo materialmente, matándolo a cariños y a literatura. Pobre joven, tan poeta y ya tan desgraciado!. - Vino, según confesión propia, a deleitarse en este preciosísimo museo histórico-arqueológico, a visitar las tumbas de Doña Salomé y de José Joaquín Pérez, a ver donde nació Galván, donde vivió Meriño, en qué lugar murió Hoatos".... (25)

La nota periodística describe a Chocano "rodeado de mosquitos, moscas y moscones".

La interviu es, desde luego, imaginaria, pero no exenta de algunos rasgos posiblemente reales. Oigamos algo:

"Otros le preguntan (a Chocano) por cuantos literatos ha habido y hay.- ¿Y Confusio?, dicele uno.- Algo confuso: creo quejeromedernista ên sultiempo.- ¿Y Rodó? Ahí ro-

(21) Artículo de Jasinto Silvestre, en "El Listin Diario", Santo Domingo, miércoles 29 de Julio de 1908. Debo las notas de la prensa dominicana principalmente al poeta Enrique Peña Barrenechea, entonces primer secretario de la Embajada del Perú en la República Dominicana, y también a José de J. Núñez y Dominguez, embajador de México en el mismo país en 1951. Núñez acaba de fallecer: abril de 1959.

(22) "El Diario de la Marina", La Habana, 9 de agosto de 1908.

(23) La composición "Los árboles de América" tiene el título de "Arboles épicos" en el volumen respectivo de "Oro de Indias" (Santiago, Nascimento, 1941), pero fue publicada con su primer nombre en el volumen titulado "Puerto Rico lírico", San Juan, s/i, s/a (1914).

(24) "Serpentinas" en "El Listin Diario", cit., 28 de Julio de 1908.

(25) Los nombres aquí mencionados corresponden a doña Salomé Ureña de Henríquez, esposa de Henríquez Carvajal y eximia poetisa; al famoso poeta dominicano Pérez y al insigne novelista Galván. Es obvio que Hostos es el autor de "Moral social" etc., apostol de la nueva cultura de Puerto Rico, fallecido en 1903 en Santo Domingo. 
dando. Es un mozo algo bolo. Gira muchísimo.- ¿Y Rueda? Idem.- ¿Y Rubén? ¡Hombre! Ese tiene nombre de judío".

Esta es la broma, pero, el mismo diario y en el mismo número, inserta un auténtico reportaje en donde Chocano advierte con manifiesta intención:

"El patriotismo no es político tan sólo. Abarca todos los detalles de las manifestaciones vitales de los hombres. Si hay una política, si hay una economía, si hay un alma patriota, también debe haber una poesía patriótica, poesía que sin incurrir en patrioterías necias, pinta amablemente la cara nacional y contribuye al arte del mundo, a la colección de medallones tradicionales, osiquicos de la tierra, con la cara de la patria",... "América que, en la naturaleza tiene cumbres que besan el cielo, ríos que son mares de agua dulce, vegetación no igualada en otra parte... merece que sus hijos la canten y sean literatos americanos".

Cuando preguntan al poeta sobre las mujeres, responde: "El ideal sería una estatua de Praxiteles en la cual insuflara Dios un alma de angel". Todo ello es ya no premonitor, como el comentario a Darío en 1896, sino comprobatorio. Chocano quisiera definir su concepto de arte pero no le dejan las solicitudes galantes y sociales. Se velobligado a improvisar de continuo. El aplauso al repentista cierralas puertás de lia autocrítica. Por de pronto, el album de "El Listín Diario" acoge este desabrido impromptu:

En las hojas impresas se reparte a la gente unos mismos ensueños y unos mismos afanes, $y$ es asi como sabe la Prensa, eternamente, el realizar un nuevo milagro de los panes. (26)

Los halagos enardecen y abruman: también adormitan. La nómina de personajes masculinos y femeninos que asisten al recital despierta sorpresa y admiración. Entre las últimas anota el cronista de "El Listín" a famosas beldades dominicanas: las señoras Octavia G. de Vidal, Estela P. de Pelerano Alfau, Leocadia de Piedra, Peiganud de Tejera, Pou vda. de Coen, Dujaric de Mar-

(26) "El Listín diario", cit. 28 de Julio de 1908. 
chena, Soler de Peynadio, Rodríguez de Gómez Álfaro, a las señoritas Consuelito Ricarł, Matilde y Flérida Lamarche, Luisita Damirón, Aurorita Ravelo, Luisa García Alfonseca, etc.

Todos se congregan el 28 de Julio. Dos días después, Chocano abandona Quiquey para volver a La Habana y pasar a Nueva York, donde le espera Fabio Fiallo que le ha invitado a compartir su modesta residencia de la calle Sesenta y uno, Oesie, cerca del Central Park. El poeta se despide mediante una breve nota periodística:

"José Santo Chocano agradece profundamente todas las atenciones que ha recibido, y se despide esperando órdenes en La Habana, Hotel Telégrafo. - Santo Domingo, Jueves 30 de Julio de 1908". (27)

La visita ha durado escasamente seis días: seis días de apoteosis. Recuerdo de ella será el artículo "Entre dos islas" que publicará el "Figaro" habanero (28) y que hemos reproducido en "Obras completas". El poela dice:

"La capital (Santo Domingo) exaltada por el tumulto de las revoluciones, hízome el efecto de una caja de hierro que hubiera sido abierta por la barreta de una violación; en los muros ví los agujeros frescos aún de proyectiles; reparé que las baldosas de las aceras habian desaparecido en el andamiaje febril de las barricadas. En la atmósfera había olor a pólvora; lacevocación delia conquista era completa" (29)

La gratitud de los dominicanos es tan viva que, aún el 20 de setiembre. la nueva revista "Blanco y negro" presenta un retrato de Chocano, de mostachos aguzados y chaleco muy blanco, junto a Federico Henriquez Carvajal. Este comenta la publicación de "un cuaderno fragmentario, artístico puñado de rosas... páginas de un libro en preparación "El Dorado" (30). Lamentamos no conocer esa pieza blibliográfica.

(27) "El Listén diario", 30 de Julio de 1908.

(28) El "Figaro", Habana, 23 de agosto de 1908.

(29) "El Listín diario", 14 de setiembre de 1908.

(30) "Blanco y negro", revista dominicana. Director propietario: Francisco A. Palau. Redactores: Apolinario Tejera, F. Henríquez y Carvajal, Manuel de J. Tronocoso y de la Concha. Año I; 20 de setiembre de 1908. 
Chocano se siente con nuevas fuerzas. Lo revela un párrafo de la mencionada crónica en "El Fígaro":

"Mi pluma ha rescatado su ala, el ala ha recuperado su pájaro y el pájaro ha dardeado los horizontes de una a otra Antilla, en un vuelo tan rápido que el libro de mis impresiones se ha deshojado como a la sacudida de una brisa que fuga". el futuro.

Explícita declaración. Debemos tenerla muy en cuenta para

De regreso a Santiago de Cuba, publica ahí, por primera vez su importante y bello soneto "Vida y arte". Los santiagueros organizan otra velada en honor del poeta. Chocano escribe a Pichardo, que le espera en La Habana:

"He trabajodo algo: dos páginas nuevas de 'El Dorado'. Una de ellas: 'Los árboles de América' va con esta fecha al 'Diario de la Marina'. Se la recomiendo. Tengo para Ud. una noticia: he escrito la leyenda del Yumuri que le está naturalmente dedicada. Espero visitar a Matanzas para ver si tengo algo más que agrēgarle".

La última exprésión desnudailepl "inétodo de composición" de Chocano, de que hablaremos en su lugar.

Una imprenta de Santiago de Cuba lanza una edición, a peso (dolar) ejemplar de lo hasta entonces escrito de "El DoradoEpopeya salvaje", otra pieza bibliográfica que tampoco he podido conocer.

La existencia de Chocano es, en esos días, acezante. No es sólo afán de gloria, sino también, y muy destacadamente, necesidad de subsistir. Ha escogido el autor de "Alma América" un arduo instrumento y un camino difícil: la pluma y la literatura. A esta se debe y todo lo que le ocurre en esos momentos se lo deberá a ella.

El 13 de agosto regresa Chocano a La Habana. El 14 se presenta en Matanzas "la ciudad de los poetas", con otro recital exitoso: ahí fecha "Yumuri" y escribe "Las cuevas de Bellamar", que publicará el "Figaro", en cuyas columnas reinicia su colabo- 
ración el 16 de agosto, apenas vuelve de Matanzas. Las "Crónicas líricas", como se titula su abigarrada sección, serán frecuentes. Poco después, asume la redacción de "Crónicas sociales", un tipo de gacetilla plagado de adjetivos elogiosos, según era y es deplorable moda en la Patria de Martí. El 20 de setiembre se presenta Chocano por última vez, ante el público de La Habana. Lo acompañan las palabras de Pichardo, Alfonso Hernández Catá y el "Conde Kostia". Los salones del Instituto Musical rebozaban de chocanistas entusiastas aquel domingo por lárgo tiempo memorable.

Entre telones, han sobrevenido incidencias respecto al proceso del Banco de España, según hemos referido en el capítulo respectivo. "El Diario de la Marina" acoge la escueta información que ya había sido desmentida y explicada por el poeta en su carta circular de enero de 1908. Se rumora que habrá extradicción, lo cual, lo sabemos a ciencia cierta, nunca fue efectivo. Fabio Fiallo lo urge a visitarle en Nueva York. El día 22 de setiembre, Chocano parte hacia Nueva Orleans, de donde seguirá al norte. El "Fígaro" del 27 da cuenta de la partida diciendo: "ha tomado al fin la nave que lo aleja de La Habana, nuestro inolvidable y admirado Santos Chocano". En la misma edición se publica "La noche lírica" del poeta, composición sintomática, de reversión o introversión, que destaca los valores líricos y hasta místicos de su temperamento. Picharda publica ahí mismo "Remolinos de fondo", dedicándolog asî́:ücailjosé Santosi Chocano, procesado". Este replicará implícitamente, desde Nueva Orleans con un soneto que, después, tuvo una equívoca y malhadada actualidad: "La gloria del proceso".

Es evidente que tan amargos hechas han madurado $-\mathrm{y}$ hasta ablandado- al poeta por dentro. Por fuera es cosa distinta: prevalecen el empaque, la osadía, la sonoridad, el cascabeleo y la arrogancia. Pero, no puede negar ya que sufre, y que sufre no para destilar rimas, sino que rima porque sufre. Bastará leer su composición "Serenamente", escrita en Habana, 1908, en la cual repite frases que usó en su correspondencia con Darío, acerca de lo ocurrido en España, y en sus comunicaciones a la prensa a propósito de lo mismo. Hela aquí:

Cuantos me han calumniado

y me han encanecido 
dieron tal magnitud a mi pecado

que me duele el no haberlo cometido.

Si grande es la aventura,

bendigo yo la trama

en que se urde el afán de la impostura

que sólo es el reverso de la fama.

Podré lanzar un grito

o hacer un loco alarde,

mas, bajo el peso de cualquier delito ..

¿justificarme yo? ¡Fuera cobarde!

¿Me echarán en olvido

porque mi lengua calla?

Nada importa vencer o ser vencido:

lo que importa es ser grande en la batalla.

Bajé desde las cumbres

a pastorear las greyes.

no "contra" sino "sobre" las costumbres,

que hay que violar para engendrar las leyes.

...Mi espíritu se ufana

porque una chispa encierra

de la luz de una estrella tan lejanaras

que no se puede ver desde la Tierra. (31)

Poema revelador y transido. No logra ocultar la angustia, más que la cólera del perseguido. Para corroborarlo, bastará la primera estrofa de su "Adios a Cuba":

Cuba de mis amores, no olvidaré tus brazos, ni como to sentiste madre de mi canción,

ni como recogisio mi lira hecha pedazos,

ni como me apretaste contra tu corazón... (32)

Está dicho todo. De nuevo las sombras arman su irreprimible conjura contra el terco y relumbrante aventurero: nubes, siempre nubes, ocultando su sol.

(31) "Serenamente, en Chocano, "Primicias de Oro de Indias", Santiago, Ed. Siglo XX, 1934, y en "Obras completas", cit, p. 637.

(32) "El Diario de la Marina", Habana, 25 de setiembre de 1908. Reproducido en "Obras completas", p. 910-911. 